\title{
Procedimentos pós-pornográficos em Lua de Mel em Buenos Aires..., do coletivo teatral Levanta FavelA
}

\section{Post-pornographic procedures in Lua de Mel em Buenos} Aires..., from Levanta FavelA theater group

Daniel dos Santos Colin ${ }^{1}$ 


\section{Resumo}

O movimento cultural pós-pornô vem se configurando como um campo artístico-político, desde a Europa até a América Latina. Este texto faz um breve panorama da pornografia mainstream sob uma perspectiva estético-discursiva para confrontá-la com práticas do pós-pornô, que se reapropriam de algumas das ferramentas discursivas do pornô convencional para subvertê-las. Apresentamos ainda uma análise do espetáculo Lua de Mel em Buenos Aires, A Mulher Crucificada e o Beijo da Besta (2016), do coletivo gaúcho Levanta FavelA, uma obra cênica que se propõe a investigar a pós-pornografia a partir da linguagem teatral.

Palavras-chave: Arte; corpo; gênero; pornografia; sexualidades

\section{Abstract}

The post-porn cultural movement is becoming an artistic-political field, from Europe to Latin America. This paper makes a brief panorama of mainstream pornography from an aesthetic-discursive perspective to confront it against post-porn practices, which repossess some of the discursive tools of conventional pornographic to subvert them. We also present an analysis of the play Lua de Mel em Buenos Aires, A Mulher Crucificada e o Beijo da Besta (2016), from the gaucho collective Gaucho raises FavelA, a scenic work that proposes to investigate post-pornography from theatrical language.

Keywords: Art; body; genre; pornography; sexualities 


\section{Examinando os discursos da pornografia mainstream heteronormativa}

A etimologia do vocábulo "pornografia" surgiu em 1857 a partir da derivação das palavras de origem grega porné (prostituta) e grafia (escrita) 2, e a partir desta genealogia, alguns autores e autoras defendem que a pornografia conforme a conhecemos hoje é uma invenção da modernidade (Ramos, 2015), expressa através de textos e imagens obscenas (Sáez, 2003) e que é praticamente impossível dissociá-la da cultura de massas, também surgida em meados do século XIX (Leite Jr., 2011). Entretanto, a origem da pornografia comercial - a qual nos interessa especificamente por sua relação transversal com o movimento pós-pornô - pode ser associada à linguagem cinematográfica e datada com mais precisão no começo dos anos 1970, considerando-se como marco inicial a tríade de filmes estadunidenses que ficaram posteriormente conhecidos como a "Idade de Ouro da pornografia": Garganta Profunda (1972) ${ }^{3}$, Atrás da Porta Verde (1972) 4 e $O$ Diabo na Carne de Miss Jones (1973) ${ }^{5}$. Nestes quase cinquenta anos, o pornô mainstream ${ }^{6}$ tem se reinventado permanentemente para atingir sua finalidade maior que é a criação de produtos potencialmente comercializáveis e, atualmente, se mantém entre as três indústrias que mais mobiliza a circulação de dinheiro em todo o mundo (Rojas, 2015)7.

Em termos estéticos, o material pornô mainstream pode ser caracterizado por propiciar a sensação de um pretenso universo real através do vídeo, remetendo a um registro documental ou ao menos expresso de forma realista. Apesar das angulações de câmera, posições sexuais coreografadas e corpos padronizados artificialmente, os filmes pornôs apresentam-se como um simulacro da realidade, cujo objetivo principal é a excitação do espectador através da articulação de três elementos-chave: mercado, corpo e papéis sexuais expressamente bem definidos. Conforme Lucía Rojas (2015), os vídeos pornográficos se caracterizam por tematizar um sexo não-reprodutivo, feito por personagens sem desenvolvimento psicológico aprofundado, com a iteração de recursos como a fragmentação dos corpos, o ritmo das cenas e a repetição dos ângulos e das narrativas, no qual o olhar masculino voyeur é sempre valorizado. No universo pornográfico produzido pelo e para o olhar masculino, em que o corpo feminino surge para ser contemplado, o protagonista onipresente é o pênis ereto, quase sempre gigantesco, desbravador de bocas, vaginas, ânus e todos os tipos de buracos, através do qual se dá a identificação entre espectador e performer. De modo geral,

\footnotetext{
${ }^{2}$ Rojas (2015) afirma que o vocábulo surgiu pela primeira vez em 1857, no Oxford English Dictionary.

${ }^{3}$ Considerado o grande paradigma inicial do pornô mainstream, Garganta Profunda (Deep Throat), foi dirigido e escrito por Gerard Damiano (aqui sob o pseudônimo de Jerry Gerard) e estrelado por Linda Lovelace e Harry Reems. É sem dúvida um dos filmes mais influentes e bem-sucedidos da indústria pornográfica, com orçamento de US\$25 mil e arrecadação oficial de US\$600 milhões, além de inúmeros subprodutos.

${ }^{4}$ Atrás da Porta Verde (Behind the Green Door) tem direção dos irmãos Artie e Jim Mitchell e é também considerado um dos filmes precursores da indústria pornográfica. Marilyn Chambers, a protagonista que não possui nenhuma fala em todo o filme, foi catapultada à condição de celebridade mainstream.

${ }^{5}$ O Diabo na Carne de Miss Jones (The Devil in Miss Jones) foi produzido, dirigido e escrito por Gerard Damiano, autor do clássico Garganta Profunda. Georgina Spelvin interpreta Justine Jones, uma mulher solitária e deprimida que comete suicídio e vai parar inadvertidamente no limbo, onde experiência encontros sexuais diversos até se tornar uma adita sexual.

${ }^{6}$ A expressão inglesa mainstream ("corrente principal" ou "fluxo principal", em português) é utilizada no âmbito da indústria pornográfica para descrever as produções convencionais realizadas por grandes empresas que visam lucro e satisfazem determinadas práticas e identidades sexuais (Rojas, 2015). No contexto deste artigo, as expressões "pornografia", "pornô" e "pornô convencional" serão utilizadas como sinônimos do supracitado conceito mainstream.

${ }^{7} \mathrm{Na}$ intenção de ater-se especificamente na análise das ferramentas estilísticas do pornô convencional tendo em vista o curto espaço destinado ao artigo, este texto opta por não entrar em outras discussões políticas acerca da indústria pornográfica mainstream, como por exemplo a opressão exercida sobre as mulheres ou a objetificação de determinados corpos. Para mais informações, ler: Lucía Rojas (2015), Maria Eduarda Ramos (2015) e Souza Júnior (2011).
} 
podemos compreender que a pornografia como gênero apresenta-se sob uma perspectiva falocêntrica heteronormativa, a qual reitera a representação coitocentrista com grande frequência, o que produz um certo saber que normatiza sexualidades, em detrimento da marginalização de outros desejos e consequentemente de outros corpos e outras sexualidades. Interessante perceber que mesmo dentro da produção de pornografia mainstream gay, os papéis sexuais entre os homens também reforçam os mesmos binarismos heteronormativos e preservam a concepção de passividade/ atividade destes papéis sexuais (Souza Júnior, 2011), um processo de construção e continuidade de relações homonormativas, que também será rejeitada por alguns movimentos políticos, como o queer.

\section{Protagonismo de outros corpos, outros desejos, outras sexualidades}

Sin porno no hay posporno (Milano, 2014, p.21)

A pós-pornografia, originada por volta da década de 1980 sobretudo através da inquietação de propostas do feminismo Pro-Sex ${ }^{8}$ e da mobilização queer, é um movimento cultural que vem se configurando de forma cada vez mais intensa como um campo artístico-político. Os sujeitos pós-pornográficos surgiram da vagina icônica de Annie Sprinkle ${ }^{9}$, efervesceram com os coletivos transfeministas de Barcelon ${ }^{10}{ }^{10}$, considerada o epicentro do movimento neste novo milênio, e vêm se alastrando em nações colonizadas por estes lados da América Latina, num trajeto geopolítico em que a ordem legitimadora de corpos está sendo sempre confrontada por meio de corporalidades, gêneros e práticas sexuais não-essencializantes. Apesar da tarefa árdua de definir o pós-pornô através de parâmetros tangíveis, graças especialmente a sua recente articulação, podemos encontrar uma primeira pista na afirmação supracitada de Laura Milano (2014), que determina uma indissociável correspondência entre o pós-pornô e a pornografia propriamente dita, em particular aquela produzida pela indústria mainstream, cujos discursos, narrativas e ideologias podem nos auxiliar a vislumbrar com maior nitidez as características imanentes ao movimento pós-pornográfico. De modo geral, os ativismos pós-pornôs assimilaram conceitos da teoria queer, como por exemplo a noção butleriana de performatividade ${ }^{11}$, bem como a ideia de contrassexualidade ${ }^{12}$ proposta por Paul B. Preciado (2014), para contradizer os discursos pornográficos hegemônicos, já que "el porno es un género (cinematográfico) que produce género (masculino/femenino). El posporno es un

\footnotetext{
${ }^{8}$ Durante a década de 1980, nos EUA, ocorreu aquilo que ficou conhecido como as Feminists Sex Wars, embate que polarizou duas vertentes do feminismo: as Pro-Sex e as Anti-Sex. Ambas facções sustentavam que a pornografia mainstream era sexista e ofensiva, mas as Pro-Sex rechaçavam a proibição e a censura à indústria pornográfica, compreendiam o pornô como uma ferramenta potente para a autonomia feminina e preconizavam a reapropriação do sexo por parte das mulheres, as quais deveriam tornar-se também sujeitos da representação de suas sexualidades.

${ }^{9}$ Parece haver um consenso em iniciar uma possível historicidade da pós-pornografia no trabalho da performer Annie Sprinkle, com especial atenção ao seu show performático Post-Porn Modernist (1989-1995). Em uma das sequências mais emblemáticas deste show solo, intitulada Public Cervix Announcement, Annie convidava o público presente a observar seu colo uterino através de um espéculo e de uma lanterna.

${ }^{10}$ A notável efervescência do pós-pornô barcelonense pode ser percebida através da pluralidade de artistas e coletivos que se uniram para produzir, discutir, festejar e difundir o movimento, quase sempre de modo autônomo, dentre as quais se destacaram Maria Llopis, Diana Pornoterrorista, Post-Op, Quimera Rosa, Go Fist Foundation, dentre outras.

${ }^{11}$ Judith Butler(2003) defende que não existe uma identidade essencial, pois acredita que essa identidade se constroi por atos repetitivos e socialmente vigiados; logo podemos concluir que gênero seria algo que performamos - um devir - em contraposição ao 'ser', fixo, estável e oposicional.

${ }_{12}$ Preciado propõe uma subversão dos mecanismos de poder cultural, social e político que elaboraram o que atualmente se entende por gênero e sexo, este uma tecnologia de dominação heterossexual. Seu conceito de contrassexualidade engloba práticas que devem ser compreendidas como tecnologias de resistência, "como formas de contradisciplina sexual" (Preciado, 2014, p.22).
} 
subgénero que desafía el sistema de producción de género y que desterritorializa el interés de los genitales a cualquier parte del cuerpo" (Sáez, 2003, s.p.). Com isto, podemos constatar outra característica que parece atravessar os discursos pós-pornográficos: a explícita crítica do movimento à cis-heteronormatividade hegemônica, aplicada através da abertura de espaços para o protagonismo de outros corpos, de outros desejos e de outras sexualidades. Os papéis sexuais são transgredidos à medida em que a base que os sustenta, no caso os binômios homem/mulher, masculino/feminino, ativo/passivo, são implodidos e substituídos por uma gama mais ampla de possibilidades de gênero e de sexualidades. Eis que a pós-pornografia vem se configurando como uma dinâmica de empoderamento dos sujeitos dissidentes frente à normatização cis-heterossexual. Nas manifestações pós-pornográficas, em que a prática punk D.I.Y.13 configura-se como eixo central, os sujeitos se concentram na auto-percepção e auto-exposição de suas sexualidades, com frequência dissidentes, utilizando-se para tanto das noções de autonomia e autogestão para produzirem seus próprios materiais pós-pornôs. Uma das estratégias de criação destes materiais, percebida sobretudo na produção audiovisual mas também com reverberações em outras linguagens, tais como literárias, performáticas, cênicas, musicais, plásticas dentre outras, é a subversão das ferramentas linguísticas e narrativas da pornografia convencional, com especial apreço pela desconstrução da relação capitalista existente na tríade 'mercado/corpo/papéis sexuais' perpetrada pelo mainstream. O pós-pornô, ao rejeitar as eventuais normas impostas pelo sistema heteronormativo e reiteradas pelo mercado, abre-se bem mais como um território de investigação, tanto no que concerne à validação de sexualidades dissidentes, quanto à experimentação de linguagens e poéticas. Importante salientar que as práticas pós-pornôs latino-americanas ${ }^{14}$ também partem destas mesmas referências teóricas, contudo parecem estar preocupadas em experimentar outros imaginários pornográficos que não somente reproduzam o pensamento colonizador, mas sim que desvelem práticas decoloniais impregnadas pelos seus próprios contextos geopolíticos, agregando às percepções europeias outras duas noções imprescindíveis: a busca por um "pós-pornô situado"15 (Castelli; Cavallero, 2012) e a exposição das dissidências corporais através de uma situación cuir ${ }^{16}$ (San Martín, 2011).

\section{Levanta FavelA e Teatro porNô: a releitura da pornografia heteronormativa}

Ao compreender que as pesquisas acerca do movimento pós-pornô na América Latina estão "engatinhando" em suas reflexões e propostas ${ }^{17}$, este texto se propõe a colaborar no crescente mapeamento de certas poéticas pós-pornográficas que

\footnotetext{
${ }^{13}$ D.I.Y. (Do It Yourself) ou "Faça Você Mesmo/Mesma".

${ }^{14}$ Sarmet (2014) defende que os termos "América Latina" e "latino-americano" devem ser assimilados como uma estratégia de afirmação geopolítica, nunca como uma identidade fixa, discurso com o qual este texto corrobora e convida os leitores e as leitoras a compreendê-lo da mesma forma.

${ }^{15}$ A proposta de Castelli e Cavallero de que compreendamos a pós-pornografia como um projeto político descolonizador, situado geográfica e politicamente, abrange outras perspectivas de subversão que não estão somente ligadas aos padrões de gênero e sexualidade, mas também assimilam o rechaço às normatizações relacionadas a questões de classe, raça, nacionalidade ou etnia.

${ }^{16}$ Pesquisadores e pesquisadoras latino-americanos têm proposto nos últimos anos a substituição da expressão anglófona queer pelo termo cuir ou kuir, uma reapropriação da palavra em contextos dos países de língua espanhola, mas perfeitamente assimilável ao português. Mais do que uma simples transposição semântica, o uso da expressão cuir configura-se como um ato performativo que reforça uma realidade político-sócio-cultural dos países latino-americanos em detrimento da utilização de teorias e noções estrangeiras acriticamente (Sarmet, 2014).

${ }^{17}$ A primeira mostra audiovisual realizada na América Latina que se auto-intituloucomo "pós-pornográfica" ocorreu apenas em 2012, na cidade de Buenos Aires, capital da Argentina.
} 
alguns pesquisadores e pesquisadoras têm realizado na América Latina nesta última década. Para tanto, segue-se a análise do espetáculo intitulado Lua de Mel em Buenos Aires, A Mulher Cruicificada e o Beijo da Besta ${ }^{18}$ (2016), que pode ser considerado um potente exemplar do movimento pós-pornô realizado no Brasil através da linguagem teatral. A montagem tem direção coletiva da Cambada de Teatro em Ação Direta Levanta FavelA ${ }^{19}$ e seu elenco é integrado pelas atrizes Danielle Rosa e Ketelin Abbady, bem como pelos atores Sandro Marques e Bruno Geraldi, os quatro revezando-se entre todas as personagens; na parte técnica, cinco pessoas completam a equipe do espetáculo, que tem duração de cerca de 120 minutos ${ }^{20}$.

A obra em questão é um dos últimos trabalhos produzidos pelo Levanta FavelA, provavelmente o coletivo teatral mais subversivo surgido em Porto Alegre no século $\mathrm{XXI}$, e é composto pela aglutinação de três textos homônimos do dramaturgo gaúcho Julio Zanotta, todos retirados da coletânea teatro porNô para atores libertinos e diretores licenciosos (2013), constituída por diversas obras dramáticas curtas inspiradas em relatos autobiográficos do dramaturgo, marcadas pela exacerbação de questões sexuais das personagens, de um ponto de vista heteronormativo, e pelo aprofundamento do interesse do escritor pela filosofia satanista. Ao compreender propostas cênicas diversas mas interdependentes entre as três narrativas da mesma encenação, optei por fazer análises individuais distintas de cada uma destas partes, com o intuito de compreender, através da fragmentação do pensamento ideológico do Levanta, alguns procedimentos pós-pornográficos utilizados pelo coletivo na construção do espetáculo. Evidente que o tríptico cênico proposto pelo grupo se concretiza poeticamente justo na interdependência das três peças; a distinção utilizada entre as obras é apenas uma ferramenta metodológica usada neste contexto com o intuito de elucidar os processos pós-pornôs da Cambada, nos quais os corpos despontam como elemento substancial em cena.

\section{A puta violentada: Lua de Mel em Buenos Aires}

Lua de Mel em Buenos Aires é a primeira parte do espetáculo-tríptico do grupo e baseia-se em um texto porNô homônimo de Zanotta, no qual a narrativa se dá sobre uma suposta viagem pós-núpcias de Clarissa e Maurílio para a capital da Argentina. A ação dramática ocorre no interior do quarto 301 do Hotel Artigas, uma "espelunca no centro de Buenos Aires" (Zanotta, 2013, p.07) durante três noites consecutivas, que marcam a divisão do texto em três partes distintas. A lua de mel do casal logo é interrompida por movimentações curiosas no quarto ao lado, o 302, as quais podem ser observadas pelos protagonistas por frestas nas paredes. No interior do outro aposento, um casal de hóspedes realiza suas fantasias sexuais representando identidades diferenciadas a cada noite, sempre diante da presença constante de dois homens misteriosos, o Senhor da

\footnotetext{
${ }^{18}$ Para uma melhor dinâmica na leitura deste texto, utilizarei a abreviação Lua de Mel... quando estiver referindo-me ao espetáculo Lua de Mel em Buenos Aires, A Mulher Crucificada e o Beijo da Besta, do Levanta FavelA.

${ }^{19}$ Para uma maior dinâmica na leitura do artigo, este texto utilizará somente as expressões 'Cambada', 'Levanta FavelA' ou simplesmente 'Levanta' para designar todo o coletivo, já que é deste modo que costumeiramente denominamos o grupo em nossas relações cotidianas. 0 coletivo possui um blog, no qual informações como histórico, trabalhos, oficinas, agenda e fotografias, são atualizadas com grande frequência: <http://levantafavela.blogspot.com.br/p/agenda-teatral.html>. Acesso em: 13 mar. 2017.

${ }^{20}$ O espetáculo estreou na Usina do Gasômetro, em Porto Alegre/RS, no ano de 2016. Desde então, o Levanta FavelA... segue fazendo temporadas de longa duração do espetáculo, geralmente apresentado todos os sábados por três a quatro meses ininterruptos, com curtos intervalos entre uma temporada e outra.
} 
Bengala e o Velho da Maleta. As tensões eróticas e as agressões vão se intensificando com o passar das noites, em ambos os dormitórios, até que o clímax ocorre quando a parede que divide os dois quartos é suspensa, revelando um espaço único e um surpreendente jogo de metalinguagem, quando o público constata de fato a representação de uma performance sexual para Maurílio, o intelectual esnobe, realizado por todas as outras personagens, inclusive a própria Clarissa, que se revela uma prostituta brasileira contratada especificamente para aquela ocasião.

A montagem do Levanta para este texto de Zanotta relega a um segundo plano as questões ligadas à intelectualidade masculina e à metalinguagem cênica para evidenciar a submissão feminina através da exacerbação de clichês de gênero, representados acima de tudo pela caracterização de Maurílio e Clarissa sob as tradicionais identidades gaúchas - o gaudério e a prenda -, representações de gênero de enorme potência no Rio Grande do Sul. Sandro entra em cena inteiramente pilchado como um gaúcho tradicionalista, projetando o sotaque característico dos pampas gaúchos, ornando sua faca com orgulho e reverenciando a carne como elemento identitário de consumo. A prenda submissa representada por Danielle surge inocente, carregando um ramalhete de flores na boca e uma boneca nas mãos, até ser transformada em prostituta por sua aparente tutora. Os símbolos de gênero vão sendo descortinados durante toda esta primeira parte do tríptico cênico, através de objetos potencialmente fálicos ostentados pelos atores homens (como faca, espeto de churrasco, bengala, mastro, dildo vibrador) ou da relação metafórica entre o corpo da mulher e a carne do churrasco, ambas temperadas pelo gaudério para serem amaciadas e consumidas pelo paladar masculino, como podemos assimilar através do solilóquio intenso de Danielle acerca da gastronomia dos pampas. Além disso, o espetáculo associa a figura da mulher com a imagem de uma égua, outro elemento do imaginário pampeiro, reproduzida na belíssima cena em que Bruno aperta o espartilho de Ketelin, tensionando as cordas como se estivesse segurando os arreios de um cavalo, ou explicitada através da canção gauchesca Morocha ${ }^{21}$, cuja letra machista é entoada ao vivo pelos homens atores na abertura do espetáculo e que, evidentemente, dá a tônica da encenação. O abuso masculino sobre o corpo feminino aparece absolutamente evidenciado na primeira parte do tríptico, em que as mulheres estão sujeitas a açoites, penetrações de objetos, agressões verbais e "apedrejamentos" cênicos. A mulher surge em Lua de Mel em Buenos Aires sob a representação feminina da prostituição em contexto culturalmente situado e, desta forma, funde-se à imagem da carne bovina pendurada em um gancho no cenário da peça: dilacerada pelo facão do macho e ostentada com orgulho.

\section{Empoderamento feminino em A Mulher Cruicificada}

A Mulher Cruicificada, segundo o próprio Zanotta (2017), já apresenta algumas referências advindas do satanismo, com destaque para as pinturas de Félicien Rops, artista belga da metade do século XIX, cujas obras lidavam com temáticas esotéricas,

\footnotetext{
${ }^{21}$ A canção gauchesca Morocha foi composta por Mauro Ferreira e Roberto Ferreira. Eis alguns trechos relevantes da letra da música: 'Aprendi a domar amanunciando égua / E para as mulher [sic] vale as mesmas regras / Animal, te para sou lá do rincão / Mulher pra mim é como redomão / Maneador nas patas e pelego na cara'.
} 
diabólicas e sexuais, com especial apreço à figura feminina inserida em contextos satanistas. A narrativa do texto é situada pelo dramaturgo durante a Revolução da Degola22, em 1893, quando Porto Alegre foi bombardeada. O texto dramático é dividido em apenas duas cenas breves, em que Frei Gazella interage com Aurora Gertrudt: na primeira parte, as personagens dialogam sobre a realidade da capital gaúcha em meio à Revolução, bem como sobre o suspeito assassinato de Monsenhor Clemente, morto após ingerir uma hóstia envenenada; a segunda cena é justamente o encontro entre Gazella e Aurora, aqui presa a uma cruz dentro da igreja, completamente nua. O frade reconhece Aurora como uma faxineira fiel que frequenta assiduamente as missas, ao passo em que ela tenta convencê-lo a subir a escada usada para crucificá-la. Como a serpente bíblica que ludibriou Eva, Aurora vai convencendo Frei Gazella a tocar seu corpo lascivamente, a comer seus excrementos e a fornicar com ela, ainda presa à cruz. Após o momento do gozo, Aurora então revela ter ela mesma colocado estricnina nas hóstias, o que permite a derradeira conclusão do frade: "Compreendo agora quem, realmente, semeia a guerra civil" (Zanotta, 2013, p.41). A ideia contida nos pensamentos de Gazella de que as mulheres estariam destruindo a humanidade encontra cumplicidade nas palavras de Rops, quando este afirma que "o homem está possuído pela mulher, e a mulher possuída pelo diabo" (Rops apud Solís, 2014, $\mathrm{s} / \mathrm{p}$.), assim como em suas pinturas em que a mulher era retratada como uma femme fatale, um dos modos de representação feminina mais populares de sua época. A imagem de uma mulher sedutora, provocativa e sensual, "culpável de muitos dos problemas do homem" (Solís, 2014, s/p.), utilizada por Felicién Rops em suas gravuras certamente reverbera na construção de Aurora Gertrudt por Zanotta e denuncia uma visão estereotipada acerca de um imaginário sexual feminino. A Cambada, a partir da premissa do dramaturgo, subverte a lógica sexista e cria uma obra feroz na qual o empoderamento das mulheres torna-se eixo central do trabalho. A 'mulher crucificada' representada pelo papel da faxineira e sedutora no contexto da dramaturgia, configura-se no espetáculo como um anjo vingador, que extermina o corpo masculino pela eucaristia e que esbraveja atada à cruz uma ameaça premonitória: 'Envenenaremos todos os senhores! Todos os homens!'.

Em A Mulher Cruicificada, o Levanta organiza sua poética feminista através inclusive da rejeição ao cristianismo, focalizando-se em imagens religiosas específicas para então subvertê-las. A partir da proposta do dramaturgo acerca da transgressão da eucaristia, representada pela hóstia envenenada para assassinar os homens, 0 espetáculo carnavaliza símbolos cristãos a partir do uso de elementos iconoclastas e pornoterroristas ${ }^{23}$, como os corpos nus simulando a cópula sobre o altar católico, com Danielle presa a uma enorme cruz; a representação da mulher devota ultrajada pela vagina de Ketelin, exposta e bolinada pelo dedo abusador de Monsenhor Clemente ou por um terço masturbatório; a bíblia completamente despedaçada, cujas páginas

\footnotetext{
${ }^{22}$ A Revolução Federalista, conhecida também como 'Revolução da Degola', foi uma guerra civil ocorrida entre facções políticas rivais encontradas no governo do Rio Grande do Sul em período imediatamente após a proclamação da República. Mais informações em: <https://brasilescola.uol.com.br/historiab/revolucao-federalista.htm>. Acesso em: 01 out. 2018.

${ }^{23}$ A performer espanhola Diana J. Torres (conhecida como Diana Pornoterrorista) se utiliza da ideia do terrorismo como uma possibilidade de resposta violenta ao poder hegemônico, para formular o conceito de pornoterrorismo, o qual seria a réplica que algumas pessoas dão "al Estado, a la lglesia o la ciencia médica que no nos permiten negociar nuestras identidades ni nuestro género ni nuestra sexualidad" (Torres, 2013, s/p.).
} 
encontram-se espalhadas pelo chão e são pisoteadas tanto pelo público quanto pelo elenco; a imagem do clero desestabilizada pelo pênis flácido de Sandro, à mostra sob o traje de frei para uma masturbação frustrada, cujo gozo nunca acontece; a oração entoada pela faxineira com versos subversivos durante o velório do Monsenhor. $A$ música aliás, aqui também, tem um papel fundamental na dramaturgia cênica de A Mulher Cruicificada através de quatro canções que reforçam o empoderamento feminino contra o patriarcalismo ancestral: enquanto Monsenhor Clemente se contorce no chão até à morte, Ketelin entoa um cântico que nos remete a um salmo cristão, mas que aos poucos revela versos disruptores ('Me entrego com tesão nesse jogo / me rasga arreganha o meu grelo / minha buceta queima como fogo / mas tua porra é fria como gelo'); as mulheres questionam o poder sexista da lgreja sobre os corpos femininos e proferem frases de anarcofunk durante a cena do aborto ('Peca pepeca pepeca / Goza peca sangra peca / Peca pepeca pepeca / Até o Papa peca'); outro anarcofunk é cantado como um convite à participação da plateia ('Vamos tirar / Vamos tirar / Vamos tirar a mulher da cruz! / Não nos calarão! / Não nos calarão!!!'); e por último, após Frei Gazella ser degolado por Aurora Gertrudt, as mulheres libertas convocam todos à luta, finalizando a segunda parte do espetáculo com a canção Fé Cega, Faca Amolada, de Milton Nascimento e Ronaldo Bastos ('Agora não pergunto mais pra onde vai a estrada / Agora não espero mais aquela madrugada / Vai ser, vai ser, vai ter de ser, vai ser, faca amolada). Tocada ao vivo, a trilha sonora proposta pelo Levanta FavelA, através de seus versos, ritmos e melodias, torna-se um dos dispositivos de resistência feminista contra a cultura hegemônica do machismo, dando voz àquelas mulheres em suas reivindicações políticas.

\section{O cu herege da travesti em O Beijo da Besta}

O Beijo da Besta é o texto que encerra o livro de Julio Zanotta (2013) e também é o espetáculo que conclui o tríptico do Levanta FavelA. O próprio dramaturgo a denomina como a obra mais satanista de todos os textos porNôs e justamente narra o encontro do Círculo de Adoradores de Satã, "uma organização de eruditos iniciados na prática do Beijo da Besta, requintada forma de expressão erótica" (Zanotta, 2013, p.94). $O$ texto se divide em cinco cenas, iniciando-se por um encontro entre o Conde Bardi e - Cardeal Cipriani, responsáveis pela retomada das atividades de antigas sucursais do Círculo de Adoradores, situadas em Porto Alegre e em Salt Lake City. A primeira cena é justamente a noite de inauguração da filial brasileira, sob o comando de Bardi, o qual, em determinado momento, relata que conheceu a travesti Anna ${ }^{24}$ numa encruzilhada da Ilha do Desterro. Anna surge apenas na terceira cena, quando é colocada sobre uma mesa de aço inoxidável e tem seu ânus invadido pelo punho de Conde Bardi, minutos antes dele beijar os cus de Anna e do Cardeal Cipriani em um ritual pagão que enfim estabelece o beijo satanista. A partir de então, Anna começa a passar por um processo que sugere a sua metamorfose em uma espécie de anjo da perdição. A peça finaliza quando a travesti, com tochas acesas em suas mãos, tenta rejeitar uma taça contendo

${ }^{24}$ Zanotta (2013) comete o lamentável equívoco de generificar a palavra 'travesti' como um termo masculino, através de artigos e adjetivos que validem essa afirmação. É amplamente reforçado nos dias de hoje que o uso mais adequado seria designar o vocábulo 'travesti' pelo feminino: 'a travesti'. 
sangue, oferecida pelo Cardeal. No entanto, Conde Bardi sentencia ameaçadoramente: "toda resistência é vã. Vocês sabem, eu já fui Satã" (Ibid., p.105).

A encenação do Levanta FavelA leva à risca a sugestão dramatúrgica de um ritual satanista e salienta esta noção, utilizando-se de elementos e símbolos frequentemente associados ao satanismo, através de simbologias clássicas, como a cruz invertida no solo que se transforma em um pentagrama durante a montagem. $O$ auge do ritual para Satã no espetáculo se institui quando toda a plateia, auxiliada pelo elenco, forma um grande círculo ao redor de Anna, interpretada por Ketelin, a qual está nesse momento nua, ostentando um pênis feito de espuma desproporcionalmente avantajado, prostrada ao centro da roda. Enquanto a atriz gargalha, o público entoa fortemente o nome mítico de Lilith, girando ao redor da travesti. A figura da travesti certamente é o elemento mais controverso da encenação, cujo fato de ser representada por uma mulher cisgênero gerou críticas ao grupo feitas por algumas pessoas trans; nada mais coerente tendo em vista estarmos todos e todas nós atravessando uma época de valorização do 'locus de enunciação'25, na qual sujeitos trans e travestis estão acertadamente revogando seus espaços que thes deveriam ser por direito ${ }^{26}$. Evidente que o grupo lida com 0 assunto de forma extremamente sensível, desde a compreensão de que, na ausência de uma atriz trans, Anna deveria ser representada por uma mulher cisgênero, até a delicadeza da percepção de Ketelin sobre sua personagem, construída a partir de sua própria convivência e relacionamentos com pessoas trans. Mesmo não estando em seu próprio 'locus de enunciação', o que a princípio invalidaria sua presença em O Beijo da Besta, a atriz serviu-se das suas relações políticas e ideológicas para instaurar um território de reflexão acerca das identidades trans e travestis.

O ânus se configura como um elemento central na última parte do tríptico. Inserido na peça explicitamente pelo dramaturgo, o cu torna-se o principal elo de relação entre os sujeitos satanistas do Círculo de Adoradores: é através da interrelação entre a boca e o cu que se instaura o ósculo de Satã, encontrando o apogeu ritualístico no ânus de Anna, compreendido por Zanotta como um ser hibridizador das essências masculina e feminina ${ }^{27}$ e posto em cena como um corpo grotesco. O grotesco bakhtiniano é evocado repetidamente durante toda a dramaturgia, através dos enfoques ao baixo ventre corporal e das ações escatológicas, dentre elas a prática de fisting anal em Anna. No espetáculo da Cambada, o fisting conduzido pelo Conde Bardi, provavelmente impraticável de ser executado ao vivo dentro das circunstâncias cênicas ${ }^{28}$, é substituído pela cena em que

\footnotetext{
${ }^{25}$ Grosfoguel define 'locus de enunciação' como "[...] la ubicación geopolítica y cuerpo-política del sujeto que habla" (Grosfoguel, 2006, p.22). A visibilização do locus de enunciação do sujeito ressalta a situacionalidade imbricada na corpo-política do conhecimento, em detrimento da lógica clássica da ego-política do conhecimento, pretensamente capaz de produzir e se apropriar de uma episteme desde um não-lugar. Em outras palavras: o 'locus de enunciação' refutaria a canônica ideia de uma epistemologia produzida por um sujeito universal, descorporalizado e des-historicizado, construtor de um conhecimento supostamente universal, objetivo e neutro. Nas últimas décadas, diversos movimentos ligados sobretudo às minorias representativas têm enfocado na valoração de seus locus de enunciação para se empoderarem politicamente.

${ }^{26}$ Como exemplo, aconselha-se a leitura do manifesto Representatividade Já. Diga não ao trans fake, elaborado pelo coletivo brasileiro Movimento Nacional de Artistas Trans, o qual reivindica, dentre outras coisas, o direito de representarem personagens trans em filmes, novelas e espetáculos teatrais, tendo em vista que estes papéis normalmente são interpretados por atores e atrizes cisgênero. 0 manifesto está disponível em: <http://www.nlucon.com/2017/03/movimento-de-artistas-trans-faz.html>. Acesso em: 24 mar. 2017.

27 "CONDE BARDI - Anna, se não é mulher, tampouco é homem. / CARDEAL CIPRIANI - É um [sic] travesti, macho e fêmea conjugados" (Zanotta, 2013, p.96).

${ }^{28}$ A expressão "circunstâncias cênicas" refere-se às decisões que a direção do espetáculo tomou em prol do ritmo e da dinâmica do mesmo, em que o fisting anal proposto pelo dramaturgo parece ter sido irrealizável em cena, já que é uma prática intensa e demorada, realizada através de procedimentos diversos (colocação de luvas, uso de lubrificante, relaxamento anal etc.).
} 
Sandro penetra o ânus da atriz com seu dedo indicador, devidamente lambuzado com algo viscoso, talvez um gel lubrificante. Em seguida, Sandro enterra seu rosto nas nádegas expostas de Ketelin e de Bruno, tal e qual havia sido proposto pelo dramaturgo, beijando os cus de ambos. As práticas anais propostas por Zanotta e ressignificadas pela Cambada em $O$ Beijo da Besta desestabilizam certos consensos acerca da heteronormatividade ao centralizar a potência política da obra artística na reverência ao cu. Para Javier Sáez e Sejo Carrascosa (2016), o cu exerce um papel fundamental na construção contemporânea da sexualidade, tendo em vista que a ele estão encarregadas potentes valorações hierárquicas de binarismos generificadores, através da segmentação entre sujeitos ativos e passivos. Desta forma, apesar de não possuir gênero, o cu se constitui como centro elementar na constituição do atual sistema de sexo-gênero, já que a identidade sexual não é estabelecida pela genitália do sujeito, mas sim por sua atitude passiva ou ativa; atitudes estas associadas historicamente a uma correlação de poder binário (penetrador-penetrado, sujeito-objeto, amo-escravo, forte-fraco). O cu portanto, em um regime cultural heterocentrado, define e enaltece a masculinidade e a feminilidade, "o que é ser homem e o que é ser mulher, [...] o que é ser um corpo valorizado e um corpo abjeto, um corpo bicha e um corpo hetero" (Saez \& Carrascosa, 2016, p.180). Com isto, a partir da perspectiva de Sáez e Carrascosa, podemos considerar que a obra cênica do Levanta subverte o dispositivo da sexualidade hegemônica ao problematizar os papéis sexuais (ativo/passivo) através da exaltação à passividade e ao propor um outro olhar sobre as práticas e políticas anais.

\section{Pela reapropriação geopolítica pós-pornográfica}

Considerando-se a sua articulação deveras recente, o pós-pornô tem agregado diversas pessoas dispostas a questionar os modos de produção de discursos de sexualidade, através da desconstrução de práticas sexuais e de imaginários pornográficos hegemônicos, que historicamente têm privilegiado o discurso heteronormativo e por ele são legitimados. Tais privilégios certamente vem contribuindo para a marginalização e invisibilização de quaisquer outras representações de corpos, gêneros e sexualidades. Para tanto, o pós-pornô apropria-se de algumas ferramentas discursivas do pornô comercial com o intuito de balizar outras sexualidades existentes, a partir da subversão destas mesmas ferramentas.

No caso do espetáculo teatral Lua de Mel..., do Levanta FavelA, esta subversão já desponta na proposta de criticar o discurso heteronormativo e sexista incutido no projeto porNô do dramaturgo. Atenta a questões de cunho feminista e racial, a Cambada articula um espetáculo pós-pornô situado, através sobretudo da irrisão de estereótipos de gênero do imaginário gaúcho, da crítica à Igreja Católica, da exaltação a práticas decoloniais do corpo e da problematizacão de papéis sexuais (ativo/passivo). Outro procedimento discursivo fortemente utilizado pelo coletivo é o emprego da trilha sonora como elo fundamental na elaboração da dramaturgia cênica: composta por músicas nacionais, as canções irradiam letras que vão reelaborando politicamente a dramaturgia de Zanotta e, desta forma, fazem coro a certas estratégias narrativas usadas por outras realizadoras do pós-pornô, em que a palavra falada ou cantada surge no corpus de suas obras para explicitar e endossar o discurso sexopolítico defendido pelas autoras das mesmas. 
Torna-se imprescindível, contudo, elucidar que o intuito da análise e da descrição das características aqui desenvolvidas não pretende em absoluto configurar-se como um 'manual do pós-pornô', pelo contrário: a potência vital do movimento dá-se justamente no convite a outras experimentações de corpos, de sexualidades e mesmo de poéticas. O território da pós-pornografia necessita ser reatualizado e reapropriado constantemente, situado em contextos geopolíticos próprios, sob o risco de tornar-se tão essencialista e enrijecido quanto o pornô convencional.

\section{Referências}

BUTLER, Judith. Problemas de gênero: feminismo e subversão da identidade. Rio de Janeiro: Editora Civilização Brasileira, 2003.

CASTELLI, Rosario; CAVALLERO, Lucía. Un posporno situado. 2012, s/p. Disponível em: <https://muestraposporno.wordpress.com/textos/un-posporno-situado/>. Acesso em: 23 mar. 2017.

GROSFOGUEL, Ramón. La descolonización de la economía política y los estudios postcoloniales: transmodernidad, pensamento fronterizo y colonialidad global. In: Tabula Rasa. Bogotá - Colombia, ISSN: 1794-2489, no.4, enero-junio 2006, p.17-48.

LEITE JR., Jorge. A pornografia contemporânea e a estética do grotesco. In: Revista (in)visível. ISSN 2182-4363. Edição zero, 2011, p. 10-23. Disponível em: <https://issuu. com/revistainvisivel/docs/revista-invisivel-zero-2011>. Acesso em: 26 fev. 2017.

MILANO, Laura. Usina posporno: disidencia sexual, arte y autogestión en la pospornografía. Ciudad Autónoma de Buenos Aires: Titulo, 2014.

PRECIADO, Beatriz. Manifesto contrassexual: práticas subversivas de identidade sexual. São Paulo: n-01 edições, 2014.

RAMOS, Maria Eduarda. Pornografia, resistências e feminismos: estratégias políticas feministas de produções audiovisuais pornográficas. Florianópolis, SC, 2015.Tese (Doutorado) - Universidade Federal de Santa Catarina, Centro de Filosofia e Ciências Humanas.

ROJAS, Lucía E. Trincheras de carne. Una visión localizada de las prácticas postpornográficas en Barcelona. España, 2015. Tesis doctoral - Universitat Autônoma de Barcelona, Departament de Comunicació Audiovisual i Publicitat.

SAEZ, Javier. El macho vulnerable: pornografía y sadomasoquismo. 2003, s/p. Disponível em: < https://www.scribd.com/document/324130769/El-Macho-Vulnerable-Pornografia-y-Sadomasoquismo>. Acesso em: 22 mar. 2017. 
SAEZ, Javier; CARRASCOSA, Sejo. Pelo cu: políticas anais. Belo Horizonte: Letramento, 2016.

SALIH, Sarah. Judith Butler e a teoria queer. Belo Horizonte: Autêntica Editora, 2015.

SAN MARTÍN, Felipe R. Diga "queer" con la lengua afuera: Sobre las confusiones del debate latinoamericano. 2011, s/p. Disponível em: <http://ensayosfeliperivas. blogspot.com.br/2011/10/publicado-en-el-libro-por-un-feminismo.html>. Acesso em: 22 mar. 2017.

SARMET, Érica. Pós-pornô, dissidência sexual e a situación cuir latino-americana: pontos de partida para o debate. In: Revista Periódicus. Salvador: UFBA, v. 1, n. 1, 2014, p. 258-276.

SOLíS, Daniela. Felicién Rops y el poder del sexo. 2014, s/p. Disponível em: <http:// culturacolectiva.com/felicien-rops-y-el-poder-del-sexo/>. Acesso em: 21 mar. 2017.

SOUZA JÚNIOR, Edílson B. Os desprezados - a agressão masculina nos vídeos pornôs e os processos de identificação e diferenciação na contemporaneidade. In: Revista (in) visível. ISSN 2182-4363. Edição zero, 2011, p.108-118. Disponível em: <https://issuu. com/revistainvisivel/docs/revista-invisivel-zero-2011>. Acesso em: 26 fev. 2017.

TORRES, Diana J. Pornoterrorismo. México: Editorial Txalaparta, 2013.

ZANOTTA, Julio. Entrevista concedida a Daniel dos Santos Colin. Porto Alegre, RS: 2017. Entrevista.

teatro porNô: para atores libertinos e diretores licenciosos. Porto Alegre: [s.e.], 2013.

Recebido em: 26/09/2018

Aprovado em: 14/10/2018 